www.jmscr.igmpublication.org

Impact Factor 5.84

Index Copernicus Value: 71.58

ISSN (e)-2347-176x ISSN (p) 2455-0450

crossref DOI: _https://dx.doi.org/10.18535/jmscr/v6i1.155

Journal Of Medical Science And Clinical Research

\title{
Risk Factors for Depression in Elderly Persons Attending the General Outpatient Clinics of the University of Uyo Teaching Hospital, Uyo
}

\author{
Authors \\ Uduakobong Morgan $^{1 *}$, Etiobong Etukumana ${ }^{2}$, Festus Abasiubong ${ }^{3}$ \\ ${ }^{1,2}$ Department of Family Medicine, University of Uyo Teaching Hospital, Uyo, AkwaIbom State, Nigeria \\ ${ }^{3}$ Department of Psychiatry, University of Uyo Teaching Hospital, Uyo, Akwalbom State, Nigeria \\ Corresponding Author \\ Dr Uduak-Obong M. Morgan \\ Department of Family Medicine, UUTH, Uyo \\ Email: uduakmorgan@gmail.com
}

\begin{abstract}
Background: The growing populations of elderly people in Sub-Saharan Africa are exposed to social changes with potential adverse effects on mental health, one of such effects is depression. Depression is a disabling illness that affects even the most basic everyday task. There is therefore a growing and urgent need for mental care in the elderly.

Aim and Objective: The aim of this study was to determine the risk factors for depression in elderly persons attending the General Out-patient Clinics of the University of Uyo Teaching Hospital.

Materials and Methods: The study was a cross-sectional descriptive study. Three hundred and ten (310) elderly persons attending the General Out- patient Clinics of the University of Uyo Teaching Hospital for medical conditions between July and September, 2014, who met the inclusion criteria, were consecutively recruited. All respondents were screened for depression using the Geriatric Depression Scale. Details of sociodemographic characteristics of the respondents as well as risk factors for depression were obtained using a semi-structured questionnaire. Data analysis was done using the Statistical Package for Social Sciences (SPSS) version 17.0 and the level of statistical significance was set at $p<0.05$.

Results: A total number of three hundred and ten subjects were recruited for the study. One hundred and seventy-seven subjects (57.1\%) were females and one hundred and thirty-three (42.9\%) were males. The female to male ratio of subjects recruited was 1.3:1. The age range of respondents were 60 and 90 years and the mean age $( \pm S D)$ of the study subjects was $67.4( \pm 6.6)$ years. From the study, significant risk factors for depression after logistic regression were loneliness and neglect, having no income, stressful life events, and financial failures. However, marital status and educational level had an association with depression when univariate analysis was done.

Conclusion: It was observed that poor income, loneliness and neglect, and stressful life events were risk factors for depression among these elderly respondents.

Keywords: risk factors, depression, elderly.
\end{abstract}




\section{Introduction}

Historical documents written by healers, philosophers, and writers throughout the ages point to the long-standing existence of depression as a health problem ${ }^{1}$. Reports have also shown that advancing age is associated with increased exposure to risk factors and vulnerability to diseases including psychological disorders, and evidence has shown that depression is one of the commonest psychological disorder often reported in the elderly worldwide. ${ }^{2,3}$ It is projected that that by 2020, depression will become the second leading cause of disease worldwide, as measured by Disability-Adjusted Life Years (DALY). ${ }^{4}$ There is therefore a growing and urgent need for mental health care in the elderly especially in developing countries like ours.

Depression in old age comprises a heterogeneous group of clinical disorders that affect adults over 60 years of age. It is an affective illness characterized by symptoms such as disturbance in mood, cognition and inability to perform physical and mental functions. It has extensive implications for the patients and their families. Besides personal and family suffering, depression in later life leads to an array of medical, psychosocial, and economic consequences including increased morbidity and mortality, increased disability, ${ }^{5}$ decreased quality of life, ${ }^{6}$ and an increase in both health care costs and health service utilization. ${ }^{7}$ Furthermore, depression characteristically complicates the course and outcome of other illnesses among older adults. ${ }^{8}$

The risk factors for depression in the elderly are not so different from those with the young population; however, the impact of these risk factors varies with age and gender. Factors such as female gender, problems related to physical health, recent loss of loved ones, fear of death, a past history of depression and family history of major depressive disorder, lack of social support, loneliness and social isolation are significant risk factors for the development of depression in the elderly. ${ }^{9}$ Older persons in developing countries like ours experience many hardships, with few able to access basic services. Traditional support systems are fast fading and the elderlies are either left alone to fend for themselves or left with the responsibility of child care with no formal support. These and many more factors have contributed to the very low ranking of Nigeria among ninety-six (96) countries in the 2015 Global Age watch Index, an index that shows how well the elderly population are faring in various countries. $^{10}$

Given the fact that the world's population is ageing rapidly, Nigeria inclusive, more attention should be given to the mental health and the overall wellbeing of elderly persons. This study seeks to find out the risk factors for depression in elderly persons attending our general out-patient clinics. Results of this study will be useful in policy making, planning and execution of awareness and health education programmes on the health, and social needs of the elderly persons.

\section{Materials and Method}

\section{Study Area}

This study was carried out at the General Outpatient Clinics of the University of Uyo Teaching Hospital (UUTH), Uyo in Akwalbom State, Nigeria. The hospital is a tertiary health institution located in Uyo, Akwa -Ibom State, South-South, Nigeria. It is a 400- bed hospital that offers specialty services to indigenes of Akwa-Ibom State and neighbouring states of Cross River, Abia and Rivers.

\section{Study design}

The study was a cross-sectional descriptive study designed to determine the risk factors for depression in elderly persons who presented for medical treatment at the General Out-patient Clinics of the University of Uyo Teaching Hospital.

\section{Sample size and selection}

The sample size for the study was determined using the formula ${ }^{11}$ below: $\mathrm{n}=\mathrm{Z}^{2} \mathrm{Pq} / \mathrm{d}^{2}$ where, 
$\mathrm{n}=$ the desired sample size (when the study population is greater than 10,000 )

$\mathrm{Z}=$ the normal standard deviate, usually set at 1.96 which corresponds to $95 \%$ confidence level.

$\mathrm{P}=$ the proportion in the target population estimated to have a particular characteristic (In this study $28 \%^{12}$ will be used)

$\mathrm{Q}=1.0-\mathrm{P}$ (where $\mathrm{q}$ is the probability of an event not occurring)

$\mathrm{d}=$ degree of accuracy desired (Set at 0.05 in this study)

Therefore, the desired sample size

$$
\begin{aligned}
\mathrm{n} & =\frac{1.96^{2} \times 0.28 \times(1-0.28)}{0.05^{2}} \\
& =\frac{3.8416 \times 0.28 \times 0.72}{0.0025} \\
& =309.78 \\
& =310
\end{aligned}
$$

The minimum sample size was three hundred and ten (310). Patients who were aged 60 years and above, with no past or present history of psychiatric illness and who gave consent were included in the study. Patients who were on medications for psychiatric illnesses and who were critically ill were not included in the study.

\section{Procedure}

All consenting respondents aged 60 and above, who met the inclusion criteria were consecutively recruited daily from Monday to Friday after the morning sorting routine until the desired sample size was obtained. Information was given to each subject in English or the Local language (Ibibio) on the research objectives and informed, written consent obtained. Participation was voluntary and confidentiality ensured. Thereafter, each individual was administered a questionnaire by the researcher to provide the information therein. Respondents who could not fill the questionnaire on their own were assisted by the researcher. The questionnaire, which was semi-structured, sought information on sociodemographic characteristics such as age, sex, marital status etc and the risk factors for depression. The Oyedeji's social classification $^{13}$ was used to ascertain the social class of the respondents and the Geriatric Depression Scale ${ }^{14}$ was used to screen the respondents for depression.

\section{Data Analysis}

Data entry and analysis were done using the Statistical Package for Social Sciences (SPSS) version 17.0. Descriptive statistics such as mean and standard deviation were used to analyse continuous variables while frequency and percentages of categorical variables were also determined. Inferential statistics such as ChiSquare $\left(X^{2}\right)$ test and odd ratios were employed to compare differences in proportions or groups. The level of statistical significance was set at $p<0.05$.

\section{Ethical Clearance}

Approval for the study was sought and obtained from the University of Uyo Teaching Hospital Research and Ethical Committee before commencement of the study.

\section{Results}

\section{Sociodemographic Characteristics of the Study Subjects}

The demographic characteristics of the study subjects are as shown in table 1. Majority of the subjects were women $(57.1 \%)$, the female to male ratio of subjects recruited was 1.3:1. The minimum and maximum ages of respondent were 60 and 90 years respectively. The mean age $( \pm \mathrm{SD})$ of the study subjects was $67.4( \pm 6.6)$ years. $74.8 \%$ of the subjects had at least attained primary level of education and most were married (51.9\%). The median monthly income was $\mathrm{N}$ $25,500.00$ with interquartile range of $\mathbb{N} 10,000.00$ $-\mathrm{N}-50,000.00$ 
Table 1 Sociodemographic characteristics of 310 elderly persons attending the GOP clinics of the UUTH, Uyo.

\begin{tabular}{|c|c|c|}
\hline Characteristics & Frequency & Percentage \\
\hline \multicolumn{3}{|l|}{ Sex } \\
\hline Male & 133 & 42.9 \\
\hline Female & 177 & 57.1 \\
\hline Total & 310 & 100 \\
\hline \multicolumn{3}{|l|}{ Educational Level } \\
\hline No Formal Education & 78 & 25.2 \\
\hline Primary Education & 130 & 41.9 \\
\hline Secondary Education & 22 & 7.1 \\
\hline Post-Secondary Education & 80 & 25.8 \\
\hline Total & 310 & 100 \\
\hline \multicolumn{3}{|l|}{ Income Source } \\
\hline None & 136 & 43.9 \\
\hline Pension & 102 & 32.9 \\
\hline Trading & 36 & 11.6 \\
\hline gifts & 14 & 4.5 \\
\hline Salary & 18 & 5.8 \\
\hline Farming & 2 & 0.6 \\
\hline Driving & 1 & 0.3 \\
\hline Carpentry & 1 & 0.3 \\
\hline Total & 310 & 100 \\
\hline \multicolumn{3}{|l|}{ Average Income grade } \\
\hline No income & 136 & 43.9 \\
\hline Less than N50,000 & 128 & 41.3 \\
\hline $\mathrm{N} 50,000<\mathrm{N} 100,000$ & 29 & 9.3 \\
\hline$>\mathrm{N} 100,000$ & 17 & 5.5 \\
\hline Total & 310 & 100 \\
\hline \multicolumn{3}{|l|}{ Religion } \\
\hline Christianity & 310 & 100 \\
\hline Islam & 0 & 0 \\
\hline Others & 0 & 0 \\
\hline \multicolumn{3}{|l|}{ Tribe } \\
\hline Ibibio & 224 & 72.2 \\
\hline Annang & 61 & 19.7 \\
\hline Oron & 13 & 4.2 \\
\hline Igbo & 9 & 2.9 \\
\hline Others & 3 & 1.0 \\
\hline Total & 310 & 100 \\
\hline \multicolumn{3}{|l|}{ Social Class } \\
\hline 1 & 35 & 12.3 \\
\hline 2 & 32 & 10.3 \\
\hline 3 & 44 & 14.2 \\
\hline 4 & 102 & 32.9 \\
\hline 5 & 97 & 31.3 \\
\hline Total & 310 & 100 \\
\hline
\end{tabular}

Proportion and level of Depression among Study subjects attending the GOP clinics of the UUTH, Uyo

The proportion and level of depression of study subjects are as shown in table 2. Of the 310 subjects recruited for the study, one hundred and forty $(45.2 \%)$ had depression while more than half, one hundred and seventy $(54.8 \%)$ were not depressed. Of the one hundred and forty depressed elderly, $127(90.7 \%)$ had mild to moderate depression and $13(9.3 \%)$ had severe depression. 
Table 2: Proportion of depression among elderly patients attending GOP clinics of the UUTH, Uyo

\begin{tabular}{lcc}
\hline Characteristics & Frequency & Percentage \\
\hline Prevalence of Depression & & \\
Not Depressed & 170 & 54.8 \\
Depressed & 140 & 45.2 \\
Total & $\mathbf{3 1 0}$ & $\mathbf{1 0 0}$ \\
Levels of Depression & & \\
Mild Depression & 127 & 90.7 \\
Severe Depression & 13 & 9.3 \\
Total & $\mathbf{1 4 0}$ & $\mathbf{1 0 0}$ \\
\hline
\end{tabular}

\section{Sociodemographic risk factors for depression} in elderly persons attending the GOP Clinics of the UUTH, Uyo

The univariate analysis of the sociodemographic risk factors for depression in the study subjects are as shown in table 3 .

The proportion of depression in the study subjects was observed to be higher in females than in males $\left(X^{2}=0.499, \mathrm{P}=0.480\right)$. There was a significant association between the educational levels of the respondents with depression. Those who had no formal education were in higher proportion than those with formal education $\left(X^{2}=\right.$ 8.757, $\mathrm{P}=0.003$ ). Also, the proportion of those having depression was higher in those who had no source of income than those who had an income source $\left(X^{2}=12.841, \mathrm{P}<0.0001\right)$. There was also a significant association between those that had experienced financial failure and those that had not with the proportion of those having depression being higher in the former $\left(X^{2}=9.862, \mathrm{P}=\right.$ 0.002). The proportion of those having depression was also higher in those that were lonely and/or neglected than those that were not and this association was statistically significant $\left(X^{2}=\right.$ 14.967, $\mathrm{P}<0.0001$ )

Analysis of the relationship between marital status and depression in the study subjects showed that the proportion of depression was higher in those who had no partners (single, divorced or widowed) than in those who were married with their partner still alive and with them $\left(X^{2}=3.69, \mathrm{P}\right.$ $=0.046$ ).

Table 3: Sociodemographic risk factors for depression in the elderly attending the GOP Clinics of the UUTH, Uyo

\begin{tabular}{|c|c|c|c|c|}
\hline \multirow[t]{2}{*}{ Risk Factors } & \multicolumn{2}{|c|}{ Depression } & \multirow[t]{2}{*}{ Chi Square } & \multirow[t]{2}{*}{$P$ value } \\
\hline & $\begin{array}{c}\text { Depressed } \\
\text { n }(\%)\end{array}$ & $\begin{array}{c}\text { Not Depressed } \\
\text { n(\%) }\end{array}$ & & \\
\hline \multicolumn{5}{|c|}{ Age group (in years) } \\
\hline $60-69$ & $83(43.7)$ & $107(56.3)$ & 0.486 & 0.922 \\
\hline $70-79$ & $48(47.1)$ & $54(52.9)$ & & \\
\hline $80-89$ & $8(50.0)$ & $8(50.0)$ & & \\
\hline $90-99$ & $1(50.0)$ & $1(50.0)$ & & \\
\hline \multicolumn{5}{|l|}{ Sex } \\
\hline Male & $57(42.9)$ & $76(57.1)$ & & \\
\hline Female & $83(46.9)$ & $94(53.1)$ & 0.499 & 0.480 \\
\hline \multicolumn{5}{|c|}{ Educational Level } \\
\hline No formal & $41(52.6)$ & $37(47.4))$ & & \\
\hline Primary & $63(48.5)$ & $67(51.5)$ & 8.757 & $0.033 *$ \\
\hline Secondary & $11(50.0)$ & $11(50.0)$ & & \\
\hline Post- secondary & $25(31.3)$ & $55(68.7)$ & & \\
\hline \multicolumn{5}{|l|}{ Income source } \\
\hline No Income & $77(56.6)$ & $59(43.4)$ & & \\
\hline Have Income & $63(36.2)$ & $111(63.8)$ & 12.841 & $0.000 *$ \\
\hline \multicolumn{5}{|l|}{ Marital Status } \\
\hline Single & $2(33.3)$ & $4(66.7)$ & & \\
\hline Married & $64(39.8)$ & $97(60.2)$ & 3.96 & $0.046^{*}$ \\
\hline Divorced & $2(33.3)$ & $4(66.7)$ & & \\
\hline Widowed & $72(52.6)$ & $65(47.4)$ & & \\
\hline
\end{tabular}

Significant $P$ value 
Table 3 (contd.): Sociodemographic risk factors for depression in the elderly attending the GOP Clinics of the UUTH, Uyo.

\begin{tabular}{lcccc}
\hline Risk Factors & \multicolumn{2}{c}{ Depression } & Chi Square & P value \\
\cline { 2 - 3 } & $\begin{array}{c}\text { Depressed } \\
\mathbf{n}(\%)\end{array}$ & $\begin{array}{c}\text { Not Depressed } \\
\mathbf{n}(\boldsymbol{\%})\end{array}$ & & \\
\hline Settlement & $51(40.5)$ & $75(59.5)$ & 1.881 & 0.170 \\
Urban & $89(48.4)$ & $95(51.6)$ & & \\
Rural & & & & $0.002^{*}$ \\
& $76(55.1)$ & $62(44.9)$ & 9.865 & \\
Financial Failure & $64(37.2)$ & $108(62.8)$ & & \\
Yes & & & & \\
No & & & & \\
& $30(73.2)$ & $11(26.8)$ & & \\
Lonely/neglected & $110(40.9)$ & $159(59.1)$ & & \\
Yes & & & & \\
No & $11(31.4)$ & $24(68.6)$ & & \\
& $12(37.5)$ & $20(62.5)$ & & \\
Social Class & $18(40.9)$ & $26(59.1)$ & & \\
$\mathbf{1}$ & $46(45.1)$ & $56(54.9)$ & & \\
$\mathbf{2}$ & $53(54.6)$ & $44(45.4)$ & & \\
$\mathbf{3}$ & & & & \\
$\mathbf{4}$ & & & & \\
$\mathbf{5}$ & &
\end{tabular}

'Significant $P$ value

\section{Association of the Clinical Factors of the Study Subjects and Depression}

The association between clinical factors and elderly depression in study subjects are as shown in table 4.

Clinical factors (History of chronic medical disease, history of a stressful life event, family history of depression and taking regular medications) and their association with depression were analysed. There was no association between depression and the presence of chronic medical illness, family history of depression, patients on regular medications and bereavement. However there was statistically significant association in respondents who has suffered a stressful life event $\left(X^{2}=8.749, \mathrm{P}=0.003\right)$.

Table 4: Association between clinical factors and depression in the respondents

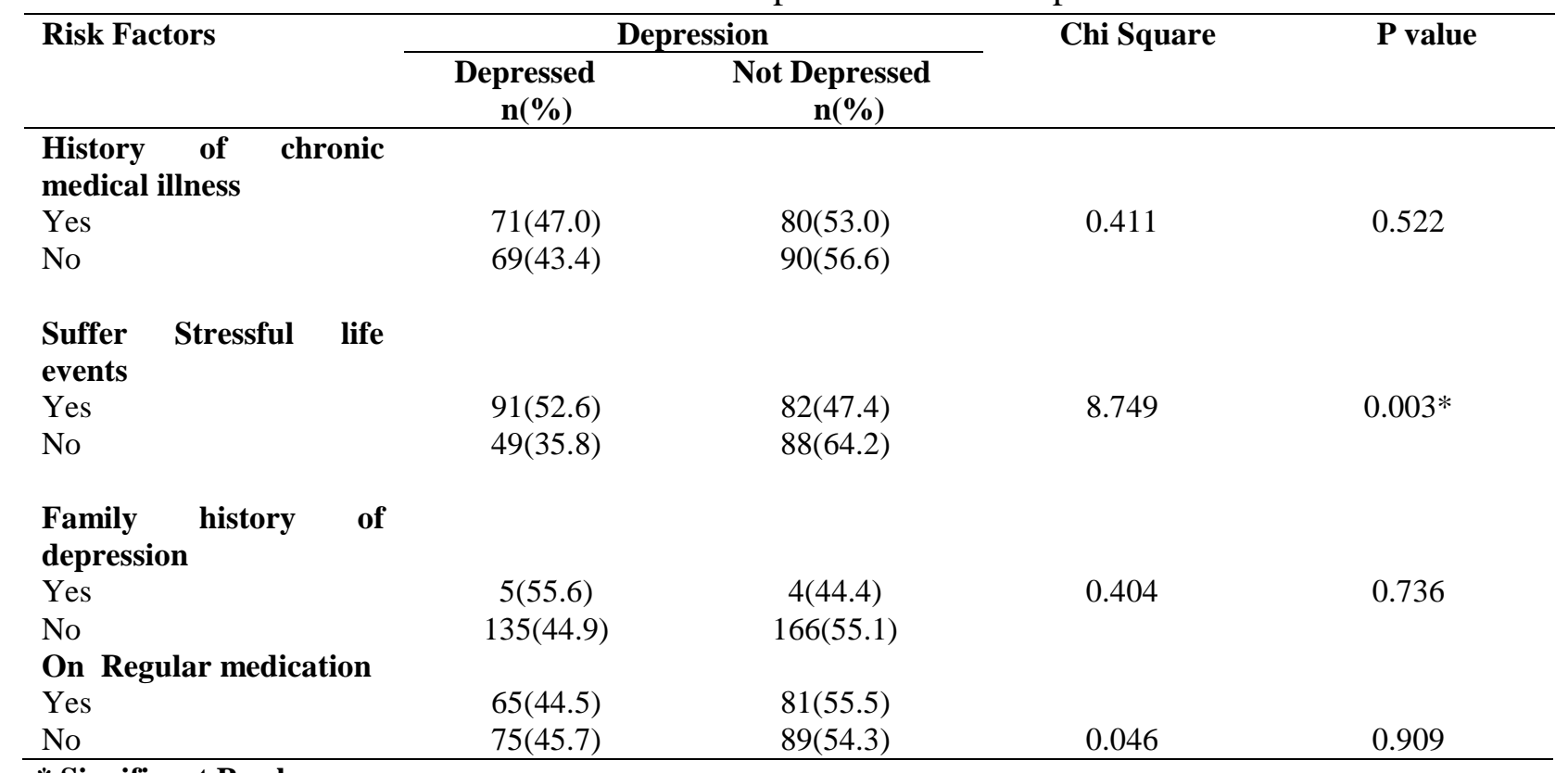

* Significant $\mathbf{P}$ value 


\section{Predictors of depression among elderly patients attending the GOP Clinics of the UUTH, Uyo}

The logistic regression of the predictors of depression among the study subjects are as shown in table 5

Logistic regression analysis of the risk factors for depression in study subjects showed that loneliness/neglect, having financial failures and no source of income and suffering a stressful life event remained strong predictors of depression in the study subjects.

Table 5: Predictors of depression among elderly subjects attending the GOP clinics of the UUTH, Uyo

\begin{tabular}{|c|c|c|c|c|}
\hline Factors & Odds Ratio & Standard Error & P value & 95\% Confidence Interval \\
\hline Lonely/neglected & 3.483 & 1.377 & $0.002 *$ & $1.604-7.561$ \\
\hline Having financial failure & 1.748 & 0.434 & $0.025^{*}$ & $1.074-2.842$ \\
\hline Suffer stressful life events & 1.765 & 0.4406 & $0.023^{*}$ & $1.082-2.879$ \\
\hline No Income & 1.995 & 0.588 & $0.019 *$ & $1.119-3.557$ \\
\hline Primary Educational level & 1.053 & 0.322 & 0.865 & $0.578-1.918$ \\
\hline Secondary Educational level & 0.988 & 0.530 & 0.983 & $0.344-2.832$ \\
\hline Tertiary Educational level & 1.431 & 0.577 & 0.374 & $0.649-3.156$ \\
\hline
\end{tabular}

\section{Discussion}

This study showed that depression was more prevalent among the female respondents than the males. Several studies have shown that females are more at risk of depression than males. Onya reported that female sex was a risk factor for depression in the elderly. ${ }^{12}$ Similar results were also reported in studies conducted over the years by Al- Shammari, Uwakwe and European Longitudinal Study on Ageing (ELSA). ${ }^{15,16,17}$ The usual explanations for higher prevalence in females is that females have a higher average number of co- morbid medical conditions, a relatively lower educational background and a higher impact of widowhood than males.

From the study, there was a significant association between the educational level of respondents and depression. Those that had no formal education showed a higher prevalence of depression than those with formal education. This finding is in agreement with those of Onya and Alshammari. $^{12,15}$ It is believed that high level of education protects people from mental disorders and may be associated with higher socioeconomic status. This high socioeconomic status usually translates to more rewarding jobs/financial status than those who are poorly educated or have no formal education.

The study also showed that those that had no partner (widowed, divorced, single) had a higher prevalence of depression than those who had partners. This finding is consistent with those from other studies. ${ }^{18,19}$ Loss of a partner is a stressful life event usually associated with psychological and emotional trauma, loneliness as well as lack of support in terms of income. This may ultimately lead to depression.

The study also showed that $43.8 \%$ of respondents had no income source while the remaining $56.2 \%$ had a source of income ranging from stipends from monthly pensions, trades, gifts and others. Elderly depression was found to be associated with lack of an income source. This finding is in agreement with studies that have shown that deterioration in financial status is among the most frequently endorsed stressful life event experienced by older adults; ${ }^{20}$ and older adults who are economically disadvantages are more likely to experience persistent depressive symptoms than those who are not. ${ }^{9,21}$ Also, a large 
proportion or respondents from the study belonged to the lower socioeconomic Class and recorded the highest depression rates. Findings from this study are in support of those from other studies $^{12,22}$. Studies have also shown that low socioeconomic status reduces capacity to manage stress and increases vulnerability to negative emotions and cognitions ${ }^{12,22}$ and that the high prevalence of depressive symptoms seen among lower social strata is due to accumulated exposure to social stressors that have occurred over time. ${ }^{20}$ In this study, there was an association between elderly depression and stressful life events. This is consistent with a meta- analysis of prospective studies of depressive symptom and disorder in adult aged 50 years or older that found that bereavement more than tripled the risk of depression, and this effect was more than any risk factor examined. ${ }^{23}$

Although there was no association of chronic medical illnesses and depression in this study, it is worthy of note that medical condition such as stroke, diabetes mellitus etc. have been found to be associated with high rates of depression. This is in agreement with several studies that have reported a high prevalence of depression in persons with co-morbid medical conditions than those with no co-morbidity. ${ }^{24-26}$ Sadly, symptoms of depression may be unrecognized in the elderly as the impact of medical co-morbidity may mask depressive symptoms. Depression further complicates the prognosis of medical illness by increasing physical disability and decreasing motivation and adherence to prescribed medications. In addition, chronic disabling conditions can be a contributory factor to suicide attempts and completions in the elderly, but timely, appropriate treatment of depression can reduce this risk.

In conclusion, it was observed that having no source of income, financial failures, loneliness and neglect as well as stressful life events were risk factors for depression among the elderly respondents in this study. These factors are consistent with the dire situations the elderly are faced with within our communities. There is an increasing need for families to strengthen the support systems especially now when the elderly is often left alone by children who have to leave in search for greener pastures. There is also a need for the government to improve the social welfare of the elderly, provide and sustain free medical and other social services, and with the private sector, put up and/or fund geriatric centers so that the specific needs of the elderly can be addressed.

\section{References}

1. Nemade R, Reiss NS, Dombeck M. Historical Understanding of Depression. Mental help.net 2007 September. Retrieved August 21, 2014 from http://www.mentalhelp.net.

2. Van Eeuwijk P. Old-age vulnerability, illhealth and care support in Urban areas. Ageing \& Society 2006; 26:61-80.

3. Van't Veer-Tazelar PJ, van Marwijk HWJ, Jansen APD, Rijmen F, Kostense PJ, van Oppen $\mathrm{P}$ Et al. Depression in old age (75+), the PIKO study J Affect Disord 2008;106:295-299.

4. Reddy MS. Depression: The Disorder and the Burden. Indian J Psychol Med 2010; 32(1): 1-2.

5. Fiske A, Wetherell JL, Gatz M. Depression in Older Adults. Annu Rev Clin Psychol. 2009; 5: 362-389.

6. Sivertsen $\mathrm{H}$, Bjoklof $\mathrm{GH}$, Engedal $\mathrm{K}$, Selbaek G, Helvik AS. Depression and Quality of Life in Older Persons. Dement GeriatrCognDisord 2015; 40: 311-339.

7. Bock JO, Luppa M, Brettschneider C, Riedel-Heller S, Bickel H. Impact of Depression on Health Care utilization and costs among Multimorbid Patients- Results from the MultiCare Cohort Study. PLUS ONE Journals 2014;9(3): e91973.

8. Espinoza R, Unutzer J. Diagnosis and management of late-life depression. $\mathrm{N}$ Engl J Med 2007; 357: 2269. 
9. Sozeri-Varma G. Depression in the Elderly: Clinical Features and Risk Factors. Aging Dis. 2012;3(6):465-471.

10. The Global AgeWatch Index 2015. Available at www.helpage.org.globalagewatch. Assessed on 15/01/18.

11. Araoye MO. Sample Size Determination. Research Methodology with Statistics for Health and Social Scoences. First Ed. Nathadex Publishers. Ilorin 2004; 115120.

12. Onya, ON, Stanley PC. Risk factors for depressive illness among Elderly GOPD attendees at UPTH, IOSR Journal of Dental and Medical Sciences (IOSRTDMS). 2013; 5(2): 77-86.

13. Oyedeji GA. Socioeconomic and cultural background of hospitalized children in Ilesa. Niger J Paediatr 1985; 12: 111- 117.

14. Yesavage JA, Brink TL, Rose TL. Development and validation of Geriatric depression screening scale: a preliminary report. J Psychiat Res 1983; 17: 37-49.

15. Al-Shammari SA. Prevalence and correlates of depression among Saudi elderly. Wiley Interscience J 1999; 14(9): 739-747.

16. Uwakwe R. Psychiatric morbidity in elderly patients admitted to nonpsychiatric wards in a General/ Teaching Hospital in Nigeria. Int $\mathbf{J}$ GeriatrPsychiatr 2000; 15 (4): 346-354.

17. Netuveli G, Wiggins RD, Hildon Z, Montgomery SM, Blane D. Quality of life at older ages: evidence from the English Longitudinal Study of Aging (Wave 1). J Epidemiol Community Health 2006; 60: 357-363.

18. Ott CH, Lenger RJ, Kulcher ST, Prigerson HG. Spousal bereavement in older adults: common, resident, and chronic grief with defining characteristics. Journal of Nervous and Mental disease 2007; 195(4): 332-341.
19. Gupta A, Mohan U, Singh SK, Manar MK, Tiwari SC, Singh VK. Screening Depression Among Elderly in a city of South East Asia. Journal of Clinical and Diagnostic Research 2015; 9(9): 1-5.

20. Girma M, Hailu M, Wakwoya A, Yohannis Z, Ebrahim J. Geriatric Depression in Ethiopia: Prevalence and Associated Factors. J Psychiatry 2016; 20: 400.

21. Mojtabai R, Olfson M, Major Depression in a community dwelling middle-aged and older adults: prevalence and 2-year and 4year follow up of symptoms. Psychol Med 2004; 34: 623 - 634.

22. Fiske A, Wetheral JC, Gatz M. Depression in Older Adults. Annu Rev ClinPsychol 2009; 5: 363-89.

23. Cole MG, Dendukuri N. Risk factors for depression among elderly community subjects: a systematic review and metaanalysis, AM J Psychiatry 2003; 160(6):1147-56.

24. Niti M, Ng T, Kua EH, Ho RCM, Tan CH. Depression and chronic medical illnesses in Asian Older Adults: the role of subjective health and functional status. International Journal of Geriatric Psychiatry. 2007; 22(11): 1087-1094.

25. Espinoza R, Unutzer J. Diagnosis and management of late-life depression. N Engl J Med 2007; 357: 2269.

26. Boing AF, Melo GR, Boing AC, MorettiPires RO, Peres KG, Peres, MA. Association between depression and chronic diseases: results from a population based study. Published 18/1/2012. Available from www.scielo.br/rsp. Assessed on 8/11/2017. 